\title{
Comparison between $E$. coli O157:H7 and Bifidobacterium spp. Activity in Almond Pudding Infant Supplemental Food
}

\author{
Rashin Sedighi', Mehrdad Tajkarimi' ${ }^{2}$, Salam A. Ibrahim² \\ ${ }^{1}$ Maternal and Child Nutrition Program, University of California, Davis, USA; ${ }^{2}$ Food Microbiology and Biotechnology Lab, North \\ Carolina A \& T State University, Greensboro, USA. \\ Email: rasedighi@ucdavis.edu
}

Received June $6^{\text {th }}, 2011$; revised July $27^{\text {th }}, 2011$; accepted August $5^{\text {th }}, 2011$.

\begin{abstract}
Almond pudding is a common traditional Iranian complementary food for infants after starting solid foods. Escherichia coli O157:H7 is one of the leading pathogenic microorganisms that cause serious foodborne disease in different populations including infants. The large intestine of breast-fed infants is colonized predominantly by bifidobacteria, which have a protective effect against acute diarrhea. The study objective of this research was to screen the survival characteristics of E. coli O157:H7 as well as four strains of Bifidobacterium subspecies (spp.) in almond pudding. The bacterial strains were studied after three and six hours of incubation at $37^{\circ} \mathrm{C}$ in-vitro. Luria-Bertani $(L B)$ broth was used as a basic medium for both Bifidobacterium spp. and E. coli experiments in anaerobic and aerobic conditions, respectively. The viability of Bifidobacterium spp. increased from $2.46 \pm 0.2$ to $6.57 \pm 1.3 \log _{10} \mathrm{CFU} / \mathrm{ml}$ in low inoculum and from $4.53 \pm 0.7$ to $7.2 \pm 0.4$ in high inoculum experiments in 6 hours. However, the growth of E. coli O157:H7 from $3.12 \pm$ 0.2 to $4.99 \pm 0.1 \log _{10} C F U / m l$ was significantly $(P<0.05)$ lower compared to Bifidobacterium spp. The results illustrate impaired growth of E. coli O157:H7 and enhanced growth of Bifidobacterium spp. in almond pudding. The finding demonstrated that almond pudding in infant's diet may indirectly enhance the protection against survival and growth of E. coli O157:H7 by increasing the Bifidobacterium spp. populations in infant's gastrointestinal system.
\end{abstract}

Keywords: Escherichia coli O157:H7, Bifidobacterium spp., Infant Complementary Food

\section{Introduction}

Foodborne outbreaks, and investigating the causes of foodborne outbreaks or diseases, have not been a high priority in developing countries because of application of basic food safety rules in buying, cooking, storage and preservation combined with pathogen resistance of exposed populations [1,2]. Changes in food consumption habits might also affect the foodborne illness rate due to cultural effects. Ladies in shopping centers in developing countries are more concern about quality of the raw materials [3]. One of the common and high morbidity diseases in children younger than 5 years old is infectious gastroenteritis. New etiologies of diarrhea such as entero aggregative E. coli $\mathrm{O} 157: \mathrm{H} 7$ have been recognized in recent decades E. coli O157:H7 causes intestinal disorders ranging from mild diarrhea to hemorrhagic colitis and severe hemolytic uremic syndrome in infants [4-7]. The predominant enterohemorrhagic E. coli serotype af- fecting humans in the United Kingdom and North America is E. coli O157:H7. In the US these infections have been associated primarily with contact with ruminant feces [8].

Several reports highlighted certain carbohydrates present in breast milk act as bifidus-specific growth factors supporting the implantation of these bacteria [9]. Lactobacillus and Bifidobacterium spp. are traditionally included in probiotic products to help protect against such effects [10]. Bifidobacterium spp. could act as a health promoting agent within the gastrointestinal tract and has been used as a probiotic for years [11].

Almond pudding is a traditional Iranian supplemental food for infants after 6 months of age. Generally, almond pudding supplement contains $10 \%$ completely smashed almond in a rice extract. Almonds (Prunus dulcis Miller D.A. Webb) are a rich source of phytochemicals and nutrients such as vitamin E. Almond consumption has been 
associated with reduction in risk factors for chronic diseases and improvement of serum lipids [12]. Almonds contain polyphenols that may have protective characteristics against cancer and cardiovascular disease [13-17]. Polyphenols and phenolic compounds presented in different food materials have antimicrobial activity that reduce bacterial survival and growth in a natural environment [18-21]. Clinical studies show that nut consumption is associated with reduced incidence of cardiovascular disease, diabetes, and some forms of cancers [16, 17].

The objective of this study was to investigate characteristics of almond pudding on survival and growth of $E$. coli O157:H7 and Bifidobacrterium spp.

\section{Materials and Method}

\subsection{Bacterial Strains}

Four strains of E. coli O157:H7 sub species, F4546 (alfalfa sprout isolate), H1730 (lettuce isolate), E0019 (beef isolate) and 944 (salami isolate) were used in this study. The strains were maintained on tryptic soy agar (TSA, Difco Laboratories, Becton Dickinson, Sparks, MD) slants at $4^{\circ} \mathrm{C}$. The strains were transferred to fresh TSB before use. Then, cultures of each strain were grown separately in TSB and Luria-Bertani (LB) broth (Difco, Becton Dickinson, Sparks, MD) at $37^{\circ} \mathrm{C}$ overnight on a shaker and transferred onto the BHI plates at $24 \mathrm{~h}$ intervals.

Two strains of bifidobacterium (Bifidobacterium spp. 36, Bifidobacterium spp. 9,) were used in this study. The strains were maintained on Lactobacilli MRS agar (Neogen, Lansling Michigan) slants at $4^{\circ} \mathrm{C}$. The strains were transferred to fresh MRS broth before use. Then, cultures of each strain were grown separately in $\mathrm{LB}$ broth at $37^{\circ} \mathrm{C}$ and transferred onto the MRS plates at $24 \mathrm{~h}$ intervals under anaerobic conditions.

\subsection{Inoculum Preparation}

The mixture of E. coli strains was made to mimic the typical infection condition. We developed a model for simulating the exposure to E. coli O157:H7. The E. coli O157:H7 strains in a preliminary experiment with LB broth. The four strains were prepared by overnight culture of individual strains at $37^{\circ} \mathrm{C}$, mixing the cultures together and centrifugation for 10 minutes at $8000 \times \mathrm{g}$ (Sorval RC 6 plus, Ashville, NC). The supernatant was decanted, and the resulting cell pellet was re-suspended in $0.1 \%$ peptone water (Becton Dickinson) to approximately $8 \log _{10} \mathrm{CFU} / \mathrm{ml}$. Serial decimal dilutions were made to achieve an initial inoculum level of $4.0 \log _{10}$ $\mathrm{CFU} / \mathrm{ml}$ before inoculation.
The Bifidobacterium strains were prepared by growing each strain at $37^{\circ} \mathrm{C}$ for 48 hours, mixing the cultures together followed by centrifugation for 10 minutes at $6000 \times \mathrm{g}$ (Sorval RC 6 plus, Ashville, NC). The supernatant was decanted, and the resulting cell pellet was re-suspended in $0.1 \%$ peptone water (Becton Dickinson) to approximately $8 \log \mathrm{CFU} / \mathrm{ml}$. Serial dilutions were made to achieve an initial inoculum levels of $3.0 \log _{10}$ $\mathrm{CFU} / \mathrm{ml}$ (low inoculum) and $5.0 \mathrm{log} \mathrm{CFU} / \mathrm{ml}$ (high inoculum) before inoculation.

\subsection{Almond Pudding Preparation}

Long grain rice (Oryza sativa) was boiled with equal volume of water for 30 minutes. The boiled water extract was filtered by a metallic kitchen filter and transferred to a sterile container.

Almond (Prunus dulcis Miller D.A. Webb) was boiled in water for 10 minutes. The whole almond (almond with skin treatment (AS)) and skinless almond (Almond treatment (AL)) was smashed thoroughly to make a homogeneous product. Almond pudding consisted of $10 \%$ $(\mathrm{w} / \mathrm{v})$ almond smash in $90 \%$ rice extract.

\subsection{Laboratory Medium Experimental Treatments}

LB broth was prepared and divided into three portions, to which almond pudding was added to levels of $0 \%$ (LB control), $50 \% \mathrm{LB}$ with AS pudding (LB/AS) or $50 \% \mathrm{LB}$ with $\mathrm{AL}$ pudding (LB/AL). Additionally, $100 \% \mathrm{AS}$ and $\mathrm{AL}$ pudding was tested. The six hour period for treatments was selected to imitate the infant's gastrointestinal digestion period. These almond pudding preparations and the LB control were used in experiments for E. coli O157:H7.

Bifidobacterium spp. preparations at low and high inoculation were compared in similar preparations of almond pudding without skin. These treatments were Almond (AL) pudding alone, LB control, and $\mathrm{LB} / \mathrm{AL}(50 \%$ LB). The culture condition for Bifidobacterium spp. has two inoculums and LB as a basic nutritional medium to mimic a closer condition to natural existence of Bifidobacterium spp. in the gastrointestinal system.

\subsection{Bacterial Enumeration Experiments}

Bacterial populations were determined for E. coli O157:H7 or Bifidobacterium spp. was according to the modified methods explained by Ibrahim et al. [22,23] by spreading samples of inoculated pudding or LB broth on BHI or MRS agar, respectively. Samples were withdrawn from inoculated almond pudding or LB broth at 0,3 and 6 hours. Samples were serially diluted in $0.1 \%$ peptone water. Appropriate dilutions $(100 \mu l)$ were spread onto dup- 
licates of each type of agar plates and CFU counts were assessed after $24 \mathrm{hr}$.

\subsection{Statistical Analysis}

Each set of experimental tests was conducted four times to determine the effect of almond pudding on the survival and growth of the tested bacterial strains. One way ANOVA statistical analysis was performed for plate counts with a significance criterion of $P \leq 0.05$ using PASW statistics 18 (SPSS, Chicago, Illinois). Statistical results were subjected to Bonferroni post hoc analysis for conservative analysis.

\section{Results and Discussion}

In this study, the growth of E. coli O157:H7 in almond pudding was investigated using almonds with skin and/or almonds without skin. E. coli in LB broth control culture increased about 2.3 fold after $6 \mathrm{~h}$ from $3.12 \pm 0.2$ to 7.45 $\pm 0.5 \log _{10} \mathrm{CFU} / \mathrm{ml}$ of LB broth. This was similar to LB broth + AS or AL puddings where the number of bacteria increased 2.5 fold. The growth of E. coli $\mathrm{O} 157: \mathrm{H} 7$ in the presence of almond pudding with and without skin were not significantly different after 6 hours. However, there was significantly less growth of E. coli $\mathrm{O} 157: \mathrm{H} 7$ in almond pudding with or without almond skin compared to
LB treated samples ( $P<0.05$, Figure 1). According to Figure 1, there was no significant difference between $E$. coli $\mathrm{O} 157: \mathrm{H} 7$ treated samples in $\mathrm{LB}+$ almond pudding $(7.79 \pm 0.68 \log \mathrm{CFU} / \mathrm{ml})$ and $\mathrm{LB}+$ almond with skin pudding $(7.78 \pm 0.71 \log \mathrm{CFU} / \mathrm{ml})$ samples. There is also a significant $(P<0.05)$ difference in $E$. coli growth between almond pudding with almond skin compared to almonds without skin that has been previously reported [13] and may need further study. However, our study focus was to investigate and create similar environment and growth condition to gastrointestinal (GS) system. It was assumed that the LB treated samples may be more similar to the GS system and mimic the nutritional condition within the GS system compare to the Almond itself. The result is also indicated significant difference between LB treated samples compare to non-LB treated samples.

The results from our study indicated that the limited growth of E. coli O157:H7 in almond pudding with and without skin might be due to interactions of other factors such as difference between nutrient supply and for the growth of E. coli O157:H7 in almond pudding compared to the LB treatments. Mandalari et al. 2010 indicate antimicrobial effect of purified almond skin extract. While another prominent ingredient in traditional Iranian pud-

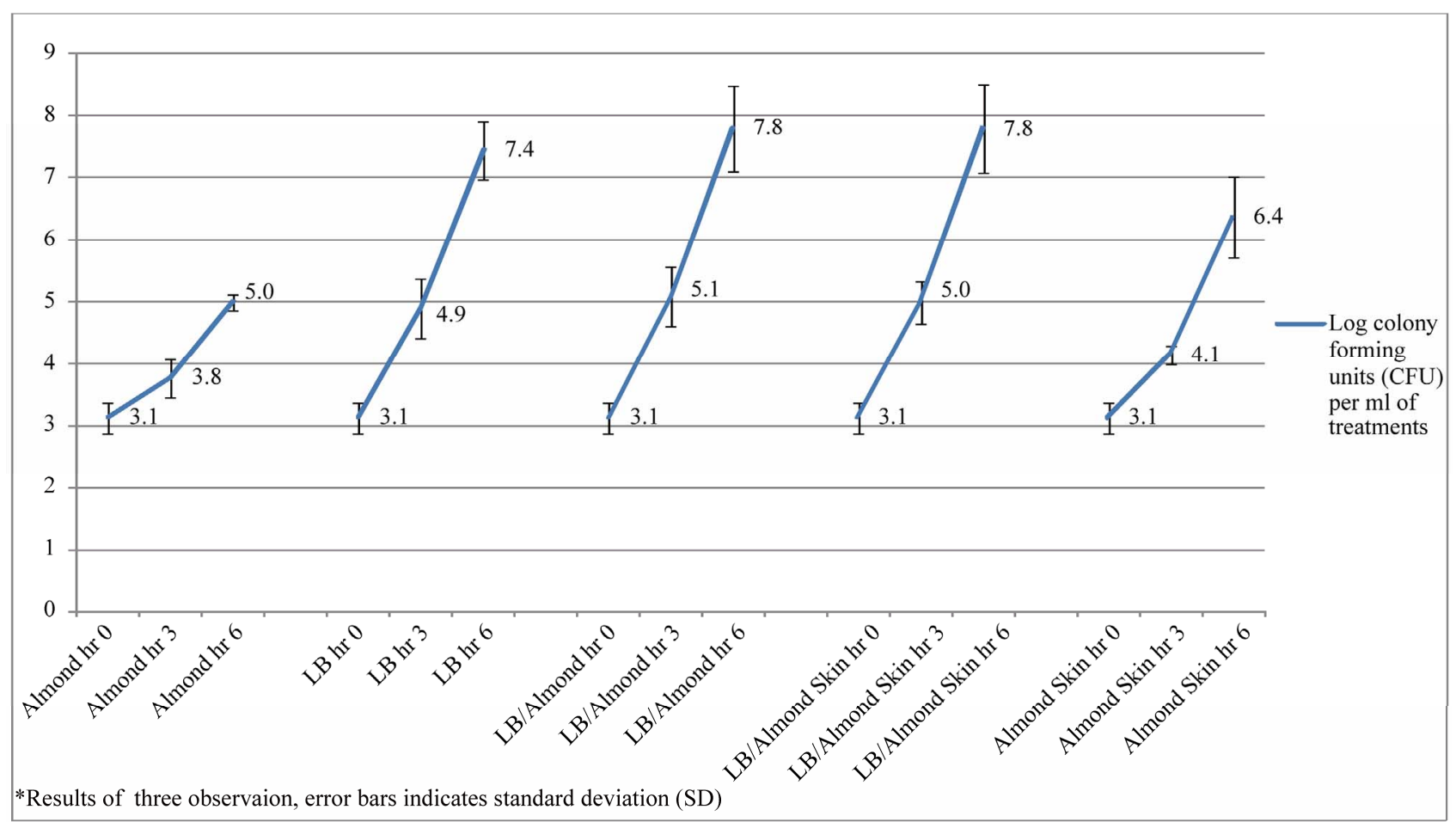

Figure 1. Survival and growth of $E$. coli O157:H7 experiments in log CFU with different treatments of Almond (AL), almond with skin (AS), Luria-Bertani broth (LB), Luria-Bertani broth with Almond (LB/AL) and Luria-Bertani broth with Almond Skin (LB/AS)* 
ding is the rice extract, Kawakami et al. showed little $E$. coli growth, and no bactericidal effects of rice extracts after $2 \mathrm{hr}$ incubation [24].

Others have shown that concentrates of polyphenols extracted from almond skin can inhibit E. coli O157:H7 growth at relatively high concentrations (Mandalri et al., 2010). While the polyphenol content of the almond pudding was not measured it is likely that, given the method of preparation, the levels of pholyphenols would not have been as concentrated. While another prominent ingredient in traditional Iranian pudding is the rice extract, Kawakami et al. showed little E. coli O157:H7 growth, and no bactericidal effects of rice extracts after a $2 \mathrm{hr}$ incubation [24].

The conditions used to test E. coli O157:H7 and Bifidobacterium spp. growth were different based on the different growth condition between the two strains. Co-culture of the bacteria was not tested because of two reasons:

1) Bifidobacterium spp. growth required reducing agents such as ascorbic acid. Results of recent study by Tajkarimi et al. indicated the antimicrobial effect of ascorbic acid against $E$. coli O157:H7. This antimicrobial effect of ascorbic acid will also be enhanced by the lactic acid which is also produced by Bifidobacterium spp. [25].

2) Bifidobacterium spp. functionality will be hindered under aerobic condition which is required for $E$. coli O157:H7 growth [26].

In another part of the study, the effect of almond pudding on the growth of Bifidobacterium spp. at high inoculation $(4.54 \pm 0.7 \log \mathrm{CFU} / \mathrm{ml})$ and low inoculation $(2.54 \pm 0.3 \log \mathrm{CFU} / \mathrm{ml})$ were compared. According to Figure 2, at low inoculation there was significant effect of the presence of almond pudding on Bifidobacterium spp. growth. After 6 hours of incubation almond pudding alone $(6.08 \pm 1.12 \log \mathrm{CFU} / \mathrm{ml})$ or almond pudding with $\mathrm{LB}(6.57 \pm 1.34 \log \mathrm{CFU} / \mathrm{ml})$ had more Bifidobacterium growth compared to the LB control $(3.20 \pm 0.24 \mathrm{log}$ CFU/ml $)(P<0.05)$. A similar affect was seen when higher inoculation levels were used. Figure 3 shows that Bifidobacterium spp. growth was greater in almond pudding (7.20 $\pm 0.43 \log \mathrm{CFU} / \mathrm{ml})$ or almond pudding with LB $(7.35 \pm 0.79 \log \mathrm{CFU} / \mathrm{ml})$ after 6 hours compared to the LB control $(5.06 \pm 0.15 \log \mathrm{CFU} / \mathrm{ml}))(P<0.05)$.

Overall comparison on Bifidobacterium spp. Experiments showed significant increase in growth in almond pudding without skin regardless of the presence of LB.

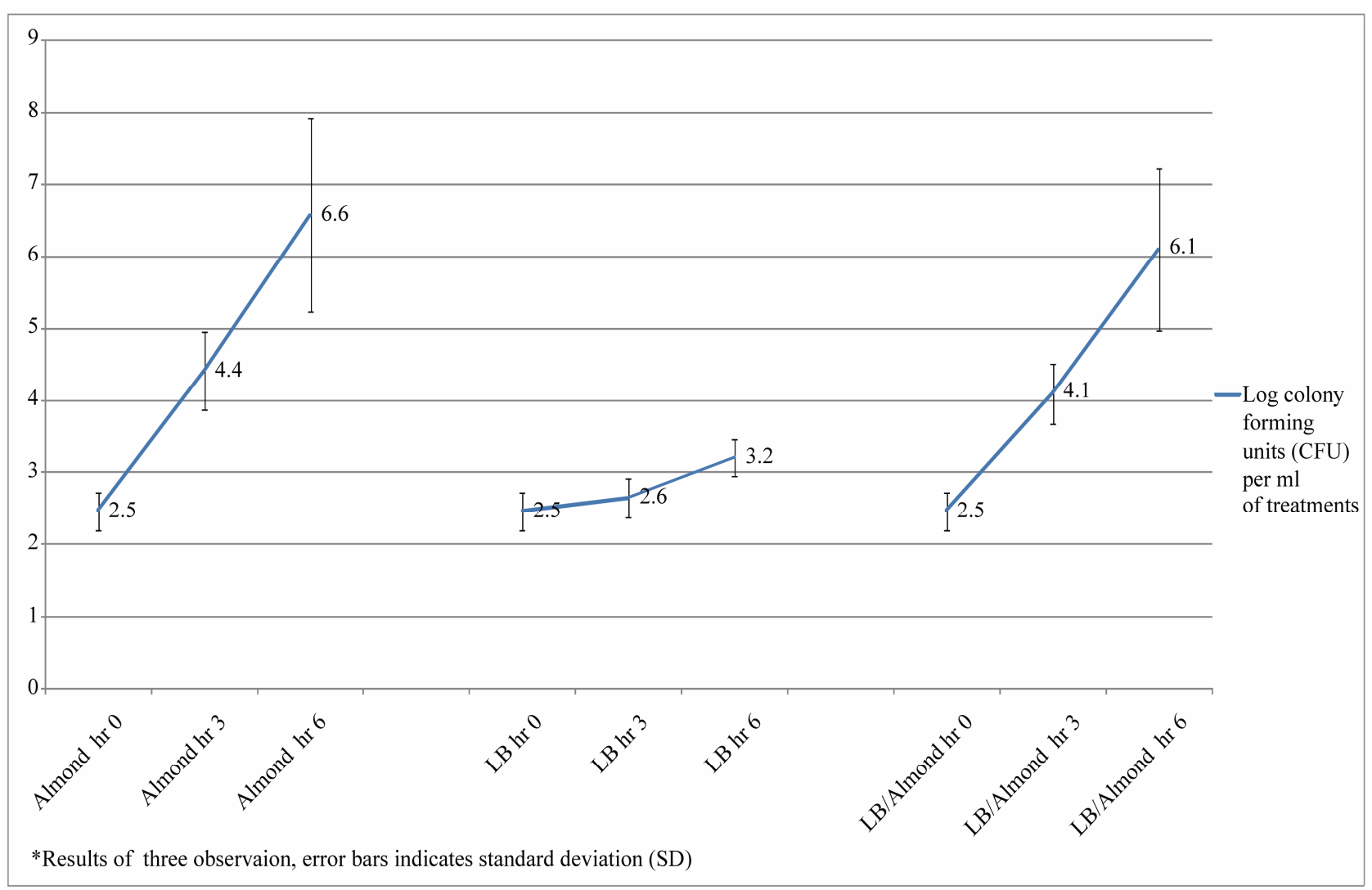

Figure 2. Survival and growth of Bifidobacterium experiments in log FU (low inoculum) with different treatments of Almond (AL), Luria-Bertani broth (LB) and Luria-Bertani broth with Almond (LB/AL)*. 


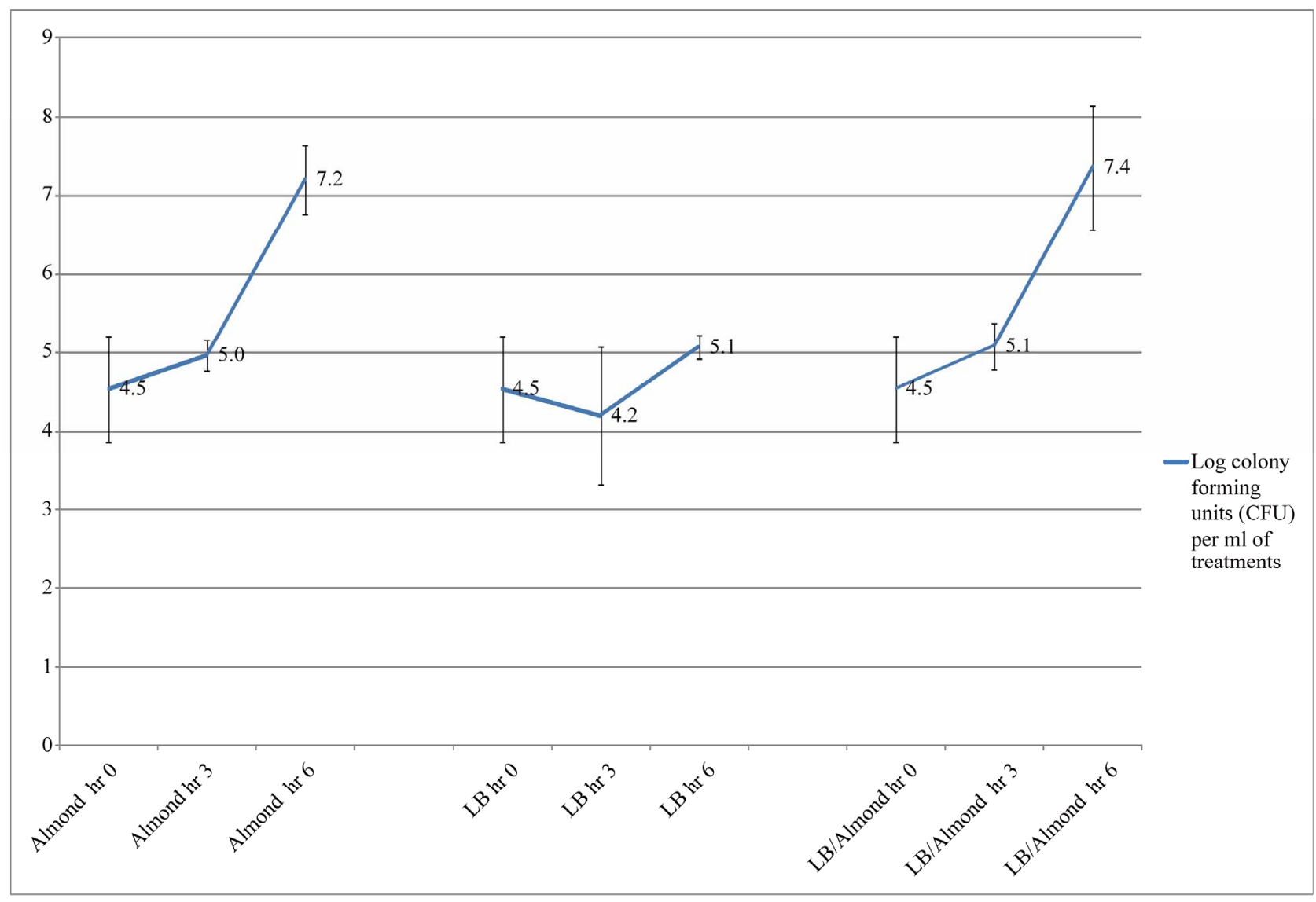

Figure 3. Survival and growth of Bifidobacterium experiments in log CFU (high inoculum) with different treatments of Almond (AL), Luria-Bertani broth (LB) and Luria-Bertani broth with Almond (LB/AL)*.

Intestinal micro flora contains complex ecosystem with at least 50 bacteria genera and several hundreds of species. Comprising several hundred species, the majority of these bacteria reside in the colon and some are believed to bring health and therapeutic benefits to the host. Bifodobacterium spp. is the safest genera and act as an opportunistic bacterium [11]. There is strong evidence of the effect of intestinal flora including bifidobacteria on human health. Bifidobacteria appear to reduce the incidence of traveler's diarrhea. They are also reportedly antagonistic towards pathogens in adults and especially in infants [27,28]. Carbohydrates can be used as growth elements for probiotics inside the intestinal tract and it could indirectly inhibit the growth of food borne pathogens including Escherichia coli, Campylobacter jejuni and Salmonella enteritidis [10]. Almond is a rich source of $22 \%$ protein and $21 \%$ carbohydrates including oligosaccharides $[29,30]$ oligosaccharide are a desirable sources as a prebiotic to promote the growth of gastrointestinal beneficial microorganisms such as Bifidobacterium spp. and Lactobacilli $[31,32]$ oligosaccharides are a third component of human milk after lactose and lipids which are mainly responsible to dominate development of microbiota including bifidobacteria [33]. Further studies need to investigate the interaction and quantitative competition between both E. coli O157:H7 and Bifidobacterium spp. in-vitro and in-vivo experiments.

\section{Acknowledgements}

Sangeetha Viswanathan is acknowledged for reviewing this article. Afagh Rafatmanesh is gratefully acknowledged for her comments about traditional almond pudding recipes.

\section{REFERENCES}

[1] T. W. S. van Veen, "International Trade and Food Safety in Developing Countries," Food Control, Vol. 16, No. 6, 2005, pp. 491-496. doi:10.1016/j.foodcont.2003.10.014

[2] A. J. Whitehead, "Elements of an Effective National Food Control-System," Food Control, Vol. 6, No. 5, 1995, pp. 247-251. doi:10.1016/0956-7135(95)00028-P

[3] S. M. Qadri and S. Kayali, "Enterohemorrhagic Escherichia coli. A Dangerous Food-Borne Pathogen," Postgra- 
duate Medicine, Vol. 103, No. 2, 1998, pp. 179-180, 185177.

[4] S. Chakraborty, A. Khan, S. Kahali, S. M. Faruque, S. Yamasaki, and T. Ramamurthy, "Infantile Diarrhoea Associated with Sorbitol-Fermenting, Non-Shiga Toxin-Producing Escherichia coli O157:H," European Journal Clinical Microbiology Infectious Disease, Vol. 22, No. 5, 2003, pp. 324-326.

[5] B. Olesen, J. Neimann, B. Bottiger, S. Ethelberg, P. Schiellerup, C. Jensen, M. Helms, F. Scheutz, K. E. Olsen, K. Krogfelt, E. Petersen, K. Molbak and P. Gerner-Smidt, "Etiology of Diarrhea in Young Children in Denmark: A Case-Control Study," Journal Clinical Microbiology, Vol. 43, No. 8, 2005, pp. 3636-3641. doi:10.1128/JCM.43.8.3636-3641.2005

[6] H. P. Li, M. Tajkarimi and B. I. Osburn, "Impact of Vacuum Cooling on Escherichia coli O157:H7 Infiltration into Lettuce Tissue," Applied and Environmental Microbiology, Vol. 74, No. 10, 2008, pp. 3138-3142. doi:10.1128/AEM.02811-07

[7] S. L. Wilkinson, "Eating Safely in a Dirty World," Chemical \& Engineering News, Vol. 75, No. 45, 1997, pp. 24-29. doi:10.1021/cen-v075n045.p024

[8] F. Dziva, P. M. van Diemen, M. P. Stevens, A. J. Smith and T. S. Wallis, "Identification of Escherichia coli O157: H7 Genes Influencing Colonization of the Bovine Gastrointestinal Tract Using Signature-Tagged Mutagenesis," Microbiology-Sgm, Vol. 150, No. 11, 2004, pp. 36313645. doi: $10.1099 / \mathrm{mic} .0 .27448-0$

[9] C. Liepke, K. Adermann, M. Raida, H. J. Magert, W. G. Forssmann and H. D. Zucht, "Human Milk Provides Peptides Highly Stimulating the Growth of Bifidobacteria," European Journal Biochemistry, Vol. 269, No. 2, 2002, pp. 712-718. doi:10.1046/j.0014-2956.2001.02712.x

[10] L. J. Fooks and G. R. Gibson, "In Vitro Investigations of the Effect of Probiotics and Prebiotics on Selected Human Intestinal Pathogens," FEMS Microbiology Ecology, Vol. 39, No. 1, 2002, pp. 67-75. doi:10.1111/j.1574-6941.2002.tb00907.x

[11] L. Meile, G. Le Blay and A. Thierry, "Safety Assessment of Dairy Microorganisms: Propionibacterium and Bifidobacterium," International Journal of Food Microbiology, Vol. 126, No. 3, 2008, pp. 316-320. doi:10.1016/j.ijfoodmicro.2007.08.019

[12] B. W. Bolling, D. L. Mckay and J. B. Blumberg, "The Phytochemical Composition and Antioxidant Actions of Tree Nuts," Asia Pacific Journal of Clinical Nutrition, Vol. 19, No. 1, 2010, pp. 117-123.

[13] G. Mandalari, C. Bisignano, M. D’Arrigo, G. Ginestra, A. Arena, A. Tomaino and M. S. J. Wickham, "Antimicrobial Potential of Polyphenols Extracted from Almond Skins," Letters in Applied Microbiology, Vol. 51, No. 1, 2010, pp. 83-89.

[14] A. J. Esfahlan, R. Jamei and R. J. Esfahlan, "The Importance of Almond (Prunus amygdalus L.) and Its byProducts," Food Chemistry, Vol. 120, No. 2, 2010, pp.
349-360. doi:10.1016/j.foodchem.2009.09.063

[15] C. Y. O. Chen and J. B. Blumberg, "In Vitro Activity of Almond Skin Polyphenols for Scavenging Free Radicals and Inducing Quinone Reductase," Journal of Agricultural and Food Chemistry, Vol. 56, No. 12, 2008, pp. 4427-4434. doi:10.1021/jf800061z

[16] X. D. Jia, N. Li, W. Z. Zhang, X. P. Zhang, K. Lapsley, G. W. Huang, J. Blumberg, G. S. Ma and J. S. Chen, "A Pilot Study on the Effects of Almond Consumption on DNA Damage and Oxidative Stress in Smokers," Nutrition and Cancer-an International Journal, Vol. 54, No. 2, 2006, pp. 179-183. doi:10.1207/s15327914nc5402_4

[17] N. Li, X. D. Jia, C. Y. O. Chen, J. B. Blumberg, Y. Song, W. Z. Zhang, X. P. Zhang, G. S. Ma and J. S. Chen, "Almond Consumption Reduces Oxidative DNA Damage and Lipid Peroxidation in Male Smokers," Journal of Nutrition, Vol. 137, No. 12, 2007, pp. 2717-2722.

[18] A. Bossi, S. Rinalducci, L. Zolla, P. Antonioli, P. G. Righetti and G. Zapparoli, "Effect of Tannic Acid on Lactobacillus Hilgardii Analysed by a Proteomic Approach," Journal of Applied Microbiology, Vol. 102, No. 3, 2007, pp. 787-795. doi:10.1111/j.1365-2672.2006.03118.x

[19] A. Al-Habib, E. Al-Saleh, A. M. Safer and M. Afzal, "Bactericidal Effect of Grape Seed Extract on MethicillinResistant Staphylococcus Aureus (MRSA)," Journal of Toxicological Sciences, Vol. 35, No. 3, 2010, pp. 357-364. doi: $10.2131 /$ jts.35.357

[20] M. M. Tajkarimi, S. A. Ibrahim and D. O. Cliver, "Antimicrobial Herb and Spice Compounds in Food," Food Control, Vol. 21, No. 9, 2010, pp. 1199-1218. doi:10.1016/i.foodcont.2010.02.003

[21] E. Pastene, F. Speisky, A. Garcia, J. Moreno, M. Troncoso and G. Figueroa, "In Vitro and in Vivo Effects of Apple Peel Polyphenols against Helicobacter Pylori," Journal of Agricultural and Food Chemistry, Vol. 58, No. 12, 2010, pp. 7172-7179. doi:10.1021/jf100274g

[22] S. A. Ibrahim, M. M. Salameh, C. W. Seo, S. A. Ahmed and M. Worku, "Evaluation of Modified M17 Broth for Growth of Probiotic Lactic Acid Bacteria and Bifidobacteria," Abstracts of Papers of the American Chemical Society, Vol. 229, 2005, pp. U52-U53.

[23] S. A. I. Siham, A. Ahmed, C. Kim and A. Shahbazi, "Significance of Bile Salt Tolerant Lactobacillus Reuteri,” In: A. Godfery, K. S. Uzochukwu, C. Shoou-Yuh, K. Vinayak, L.-T. Stephanie, R. Gudigopuram and N. Emmanuel, Eds., Proceesings of the 2007 National Conference on Environmental Sceince and Technology, Springer, Greensboro, 2009, pp. 17-23.

[24] Y. Kawakami, K. Oana, M. Hayama, H. Ota, M. Takeuchi, K. Miyashita, T. Matsuzawa and K. Kanaya, "In Vitro Bactericidal Activities of Japanese Rice-Fluid against Helicobacter Pylori Strains," International Journal of Medical Sciences, Vol. 3, No. 3, 2006, pp. 112-116.

[25] M. Tajkarimi and S. A. Ibrahim, "Antimicrobial Activity of Ascorbic Acid Alone or in Combination with Lactic Acid on Escherichia coli O157:H7 in Laboratory Medium and Carrot Juice," Food Control, Vol. 22, No. 6, 2011, pp. 
801-804. doi:10.1016/j.foodcont.2010.11.030

[26] A. M. Mortazavian, M. R. Ehsan, S. Sohrabvandi and J. A. Reinheimer, "MRS-Bile Agar: Its Suitability for the Enumeration of Mixed Probiotic Cultures in Cultured Dairy Products," Milchwissenschaft-Milk Science International, Vol. 62, No. 3, 2007, pp. 270-272.

[27] M. Gagnon, E. E. Kheadr, G. Le Blay and I. Fliss, "In Vitro Inhibition of Escherichia coli O157:H7 by Bifidobacterial Strains of Human Origin," International Journal Food Microbiology, Vol. 92, No. 1, 2004, pp. 69-78. doi:10.1016/j.ijfoodmicro.2003.07.010

[28] L. Ebringer, M. Ferencik and J. Krajcovic, "Beneficial Health Effects of Milk and Fermented Dairy Products," Folia Microbiologica, Vol. 53, No. 5, 2008, pp. 378-394. doi:10.1007/s12223-008-0059-1

[29] U. S. D. O. Agriculture, "USDA Commodity Food A256, A264 United States Department of Agriculture,” 2011. http://www.nal.usda.gov/fnic/foodcomp/cgi-bin/list_nut_ edit.pl

[30] D. Nabarlatz, C. Torras, R. Garcia-Valls and D. Montane, "Purification of Xylo-Oligosaccharides from Almond Shells by Ultrafiltration," Separation and Purification Technology, Vol. 53, No. 3, 2007, pp. 235-243. doi:10.1016/j.seppur.2006.07.006

[31] L. Siew-Wai, T. Zi-Ni, A. A. Karim, N. M. Hani and A. Rosma, "Fermentation of Metroxylon Sagu Resistant Starch Type III by Lactobacillus sp and Bifidobacterium bifidum," Journal of Agricultural and Food Chemistry, Vol. 58, No. 4, 2010, pp. 2274-2278. doi: $10.1021 / \mathrm{jf} 903820 \mathrm{~s}$

[32] Q. Shen, K. M. Tuohy, G. R. Gibson and R. E. Ward, "In Vitro Measurement of the Impact of Human Milk Oligosaccharides on the Faecal Microbiota of Weaned FormulaFed Infants Compared to a Mixture of Prebiotic Fructooligosaccharides and Galactooligosaccharides," Letters in Applied Microbiology, Vol. 52, No. 4, 2011, pp. 337- 343. doi:10.1111/j.1472-765X.2011.03005.X

[33] R. Gonzalez, E. S. Klaassens, E. Malinen, W. M. de Vos and E. E. Vaughan, "Differential Transcriptional Response of Bifidobacterium Longum to Human Milk, Formula Milk, and Galactooligosaccharide," Applied and Environmental Microbiology, Vol. 74, No. 15, 2008, pp. 46864694. doi:10.1128/AEM.00122-08 